\title{
Effect of major CYP2C19 genetic polymorphisms on Helicobacter pylori eradication based on different treatment regimens
}

\author{
MALEK ZIHLIF $^{1}$, BANAN BASHAIREH ${ }^{1}$, MOHAMMED RASHID $^{2}$, ZAID ALMADANI $^{1}$ and YAZUN JARRAR ${ }^{3}$ \\ ${ }^{1}$ Department of Pharmacology, ${ }^{2}$ Department of Internal Medicine, Faculty of Medicine, The University of Jordan, \\ Amman 11492; ${ }^{3}$ Department of Pharmacy, Al-Zaytoonah University of Jordan, Amman 11731, Jordan
}

Received July 31, 2021; Accepted October 12, 2021

DOI: $10.3892 /$ br.2021.1485

\begin{abstract}
Helicobacter pylori (H.pylori) infection is a global issue. Its eradication in affected individuals is important to prevent several further complications that may occur if left untreated. Proton pump inhibitors (PPIs) serve an important role in the eradication regimens of $H$. pylori. PPIs are metabolized primarily through the CYP2C19 enzyme in the liver. Inter-individual variation in the response to eradication treatment may partly be due to variations in the metabolism of PPIs. The aim of this study was to determine whether there was any association between CYP2C19 genetic polymorphisms and the response to eradication therapy amongst Jordanians infected with $H$. pylori receiving lansoprazole-based regimens. The present study was approved by the Institutional Review Board of The University of Jordan Hospital. A total of 141 patients infected with $H$.pylori were genotyped for the polymorphisms CYP2C19*2 and CYP2C19*17 using the PCR-restriction fragment length polymorphism assay method. Patients received lansoprazole-based triple or sequential therapy. The assessment of eradication was performed using either a $H$. pylori stool antigen test or from feedback from patients regarding their improvement. Eradication rates were $84.6 \%$ and $64.5 \%$ in the intermediate-metabolizer and extensive-metabolizer group, respectively. This difference was not statistically significant. Moreover, no significant association was found between the carriers of the CYP2C19*17 polymorphism and the response to eradication therapy. These findings suggest that there was no significant association between the CYP2C19 genotype and the response to eradication therapy amongst Jordanians infected with $H$. pylori.
\end{abstract}

Correspondence to: Professor Malek Zihlif, Department of Pharmacology, Faculty of Medicine, The University of Jordan, Queen Rania Street, Amman 11492, Jordan

E-mail: m.zihlif@ju.edu.jo

Key words: CYP2C19 genotype, Helicobacter Pylori, proton pump inhibitors

\section{Introduction}

Helicobacter pylori (H. pylori) infection is problem faced by individuals across the world. Half the world's population will be infected with this bacterium at least once throughout their life (1). H. pylori infection should be eradicated to prevent any further complications that may arise due to the effects of $H$. pylori on the gastric mucosa, such as chronic active gastritis, peptic ulceration, mucosa-associated lymphoid tissue lymphoma and gastric adenocarcinoma (2). The majority of eradication regimens consist of proton pump inhibitors (PPIs) combined with two, antibiotics, including clarithromycin, metronidazole or amoxicillin (2). PPIs are acid-inhibitors used in the management of several gastrointestinal disorders. They act as irreversible inhibitors of the $\mathrm{H}^{+} / \mathrm{K}^{+}$ATP enzyme system, thus affecting acid secretion in the gastric tract (3). The efficacy of numerous PPIs in the treatment of $H$. pylori infection varies amongst individuals, which may be partially related to variations in the PPI metabolic pathway (4). It has been shown that PPIs are primarily metabolized through CYP450 enzymes, particularly CYP2C19 (5). CYP2C19 is highly polymorphic, and $>30$ variant alleles have been identified (4).

In the Jordanian population, CYP2C19*2 is the principal defective allele (6), which is hypothesized to exhibit reduced enzymatic activity. A previously discovered defective allele for the CYP2C19 enzyme was CYP2C19*17, which is associated with increased enzymatic activity (7). A total of 4 phenotypes have been identified on the basis of PPI metabolism: Ultra-rapid metabolizers (homozygous and heterozygous for the mutant type, CYP2C19*17) (8), extensive metabolizers (homozygous for the wild type, CYP2C19*1), intermediate metabolizers [heterozygous; carrying one mutant allele (CYP2C19*2) and one wild type allele (CYP2C19*1)] and poor metabolizers (homozygous for the mutant type, CYP2C19*2) (4). There is no information available regarding the effect of the CYP2C19 genotype on the eradication of $H$. pylori amongst the Jordanian population to the best of our knowledge. Therefore, the aims of the present study were to determine the genotype and allele frequencies of CYP2C19*2 and CYP2C19*17 polymorphisms amongst Jordanian patients infected with $\mathrm{H}$. pylori, and to determine whether there was a relation between these genetic polymorphisms and a patient's response to eradication therapy against $H$. pylori. 


\section{Materials and methods}

Study design. This study was conducted in The Gastrointestinal Unit of The University of Jordan Hospital. Every patient provided signed informed consent to participate in this study. The study and the consent form were approved by the Institutional Review Board of The University of Jordan Hospital. Patients who had been diagnosed with H.pylori were interviewed after the completion of the endoscopy procedure, and the information related to each patient was recorded. Patients with $H$. pylori infection received either triple therapy or sequential therapy as shown in Table SI.

Study cohort. The study population were patients diagnosed with H.pylori infection using a Serim PyloriTek ${ }^{\circledR}$ Test kit (Serim Research Corporation) during the endoscopic procedure. The required sample size was calculated to be $\sim 136$ subjects, based on information from previous studies amongst Jordanians and using the Cochran's formula (9). In total of $230 \mathrm{H}$. pylori infected patients, without serious comorbidities, visited The University of Jordan Hospital in the previous year, according to the records of The Jordan University Hospital. It was calculated that a sample size of 139 patients would represent the $H$. pylori infected patients attending The University of Jordan Hospital using the power of test $1-\beta=0.8,5 \%$ margin of error, and $95 \%$ confidence level.

The inclusion criteria of the patients were Jordanians aged between 17-75 years old who had a positive result on the Serim PyloriTek ${ }^{\circledR}$ Test. The exclusion criteria of the patients were: Patients with serious comorbidities, pregnant women, patients allergic to the amoxicillin, metronidazole or lansoprazole, and patients on other PPIs, such as omeprazole.

Accordingly, 149 patients were included in this study, 53.7\% were females $(n=80)$ and $46.3 \%$ were males $(n=69)$. The age range of the patients was 17-73 years. Blood samples were collected from 141 patients and a stool test was obtained from 71 subjects. However, 17 patients were excluded from this study for the following reasons: 8 patients did not receive the chosen treatment regimens, and another 9 patients did not complete the treatment regimen.

Blood sample collection and extraction of genomic DNA. From each patient, 3-5 $\mathrm{ml}$ whole venous blood was collected in EDTA tubes and stored at $4^{\circ} \mathrm{C}$. DNA was extracted from the whole blood using commercial kits for genomic DNA extraction (Wizard Genomic DNA Purification kit; Promega Corporation), according to manufacturer's protocol.

Genotyping of CYP2C19*2 (681G>A, rs42442850), CYP2C19*17 (-806C $>T$, rs 12248560) alleles. Amplification of specific sites in the CYP2C19 gene containing the genetic variants of interest, CYP2C19*2 and CYP2C19*17, was performed as described by previously (10). The PCR condition were as follows: $200 \mathrm{ng}$ extracted genomic DNA was amplified in a $20 \mu \mathrm{l}$ reaction volume containing $0.5 \mathrm{mM} \mathrm{MgCl}_{2}$, $1 \mathrm{X}$ Taq polymerase buffer (New England Biolabs, Inc.), $0.1 \mathrm{mM}$ dNTPs, 15 pmoles each of the forward and reverse primers (Integrated DNA Technologies, Inc.), and 0.7 unit Taq DNA polymerase (New England Biolabs, Inc.). The thermocycling conditions were $94^{\circ} \mathrm{C}$ for $5 \mathrm{~min}$; followed by 35 cycles of denaturation at $94^{\circ} \mathrm{C}$ for $45 \mathrm{sec}$, annealing at $55^{\circ} \mathrm{C}$ for $30 \mathrm{sec}$, and elongation at $72^{\circ} \mathrm{C}$ for $40 \mathrm{sec}$. The primer sequences were: CYP2C19*17 variant forward, 5'-AAATTTGTGTC TTCTGTTCTCAATG-3' and reverse, 5'-AGACCCTGGGAGAACAGGAC-3'; and CYP2C19*2 variant forward, 5'-CAGAGCTTGGCAATATTG TATC-3' and reverse, 5'-ATACGCAAGCAGTCACATAAC-3'.

The PCR products were digested by SmaI restriction enzyme (New England Biolabs, Inc.) at $25^{\circ} \mathrm{C}$ for $1 \mathrm{~h}$ for identification of the CYP2C19*2 allele. The PCR products were also incubated with the NsiI restriction enzyme (New England Biolabs, Inc.) at $37^{\circ} \mathrm{C}$ overnight to detect the CYP2C19*17 allele (10).

The PCR products were separated on $1.5 \%$ agarose gel by applying an 125 A current for $20 \mathrm{~min}$. The gel was stained by the Redsafe dye (Intron Biotechnology, Inc.).

Stool sample collection. Each patient was asked to bring a stool sample $\geq 1$ month after completion of eradication therapy, this was used to determine whether the treatment for $H$. pylori infection had been successful. A positive result indicated a failure of the treatment and a negative result indicated success.

This test was performed using the Wondfo One Step H. pylori Feces Test (Wondfo, China; cat. no. WO6381115), according to the manufacturer's protocol. Briefly, the test kit contained a combination of $H$.pylori antibody coated particles and anti-mouse $\mathrm{IgG}$ antibody to qualitatively and selectively detect $H$. pylori antigens in stool samples. In the test line region of the kit, H. pylori antibody was immobilized. After the addition of the specimen into the test kit, the specimen was absorbed into the kit and mixed with the antibody-dye conjugate.

Statistical analysis. Normally distributed continuous variables, such as age, were analyzed using ANOVA followed by a Tukey's HSD post-hoc test. A Pearson's $\chi^{2}$ and Fisher's exact test were used for independent variables to determine the association between CYP2C19*2 and CYP2C19*17 polymorphisms and response to eradication therapy, comparison between sequential and triple therapy, the association between response to eradication therapy and phenotypes.

$\mathrm{P}<0.05$ was considered to indicate a statistically significant difference. Odds ratios for significant association were given with a 95\% confidence interval. All statistical analyses were performed using SPSS Inc. version 23 (IBM Corp.).

\section{Results}

Genotype frequency of G681A and C-806T polymorphisms amongst Jordanians infected with H. pylori. For the CYP2C19 G681A genotype, the wild type genotype GG was seen (data not shown) in 118 patients (83.7\%), the heterozygous genotype GA was seen in 23 patients (16.3\%) and the homozygous variant genotype AA was not seen in any patient. Regarding the CYP2C19 C-806T genotype, the wild type genotype CC was seen (data not shown) in 79 patients (56\%), the heterozygous genotype CT was seen in 53 patients (37.6\%), and the homozygous variant genotype TT was seen in 9 patients $(6.4 \%)$.

Accordingly, the majority of the patients (54.8\%) in the present study carried the extensive-metabolizing phenotype 
Table I. Distribution of the G681A genotype amongst responders and non-responders to eradication therapy based on the HpSA test and degree of symptoms.

\begin{tabular}{|c|c|c|c|c|}
\hline \multirow[b]{2}{*}{ Method of assessment } & \multicolumn{2}{|c|}{ G681A genotype, n (\%) } & \multirow[b]{2}{*}{ Total } & \multirow[b]{2}{*}{ P-value ${ }^{a}$} \\
\hline & GG & GA & & \\
\hline HpSA test & & & & 0.198 \\
\hline Responder & $34(51.5)$ & $11(16.7)$ & 45 & \\
\hline Non-responder & $19(28.8)$ & $2(3.0)$ & 21 & \\
\hline Total & 53 & 13 & 66 & \\
\hline Reporting of symptoms & & & & 0.354 \\
\hline Complete improvement & $37(39.4)$ & $3(3.2)$ & 40 & \\
\hline Partial improvement & $21(22.3)$ & $5(5.3)$ & 26 & \\
\hline No improvement & $24(25.5)$ & $4(4.3)$ & 28 & \\
\hline Total & 82 & 12 & 94 & \\
\hline
\end{tabular}

${ }^{\text {a} F i s c h e r ' s ~ e x a c t ~ t e s t . ~ H p S A, ~ H . ~ P y l o r i ~ s t o o l ~ a n t i g e n . ~}$

followed by the ultra-rapid-metabolizing phenotype (34\%), whereas only a small percentage $(8.5 \%)$ carried the extensive/ intermediate-metabolizing phenotype. None of the patients carried the poor metabolizing phenotype.

Response to $H$. pylori eradication treatment. The response to eradication treatment of $H$. pylori was assessed using two methods; a H. pylori stool antigen (HpSA) test and improvement in symptoms after completion of treatment.

Out of 71 patients, $31 \%$ did not exhibit eradication of H. pylori and $69 \%$ responded to treatment. Follow up with patients was performed for 100 patients who already had symptoms. They were asked about the degree of symptom improvement after completion of treatment. Improvement was classified into three degrees: Complete improvement, partial improvement and no improvement. Out of the 100 patients, $30 \%$ exhibited no improvement of symptoms, whereas $70 \%$ showed some degree of improvement (27\% had partial improvement and $43 \%$ had complete improvement). Correlation between the results of the HpSA test and symptoms improvement was performed for 60 patients. It was found that there was a significant association (Pearson's $\chi^{2}, \mathrm{P}=0.013$ ) between the HpSA test result and the degree of symptom improvement. Of the responders, based on the HpSA test, $73.8 \%$ showed improvement (partial or complete) of symptoms, and $61.1 \%$ of the non-responders showed no improvement of symptoms.

Patients who were infected with $H$. pylori were treated with either triple therapy or sequential therapy. The efficacy of the two regimens on the eradication of $H$. pylori based on the HpSA test results and the degree of improvement of symptoms were assessed. Accordingly, there was no significant difference in the efficacy of the two treatment regimens (Fisher's exact test, $\mathrm{P}>0.05$ ). Amongst the non-responder group, 50\% received triple therapy and $50 \%$ received sequential therapy, and amongst the responder group, 54\% received triple therapy and $46 \%$ received sequential therapy. Additionally, there was no significant difference in the efficacy of the two treatment regimens depending on the patients' symptoms (Fisher's exact test, $\mathrm{P}>0.05$ ). Amongst patients who did not improve, $60 \%$ received triple therapy and $40 \%$ received sequential therapy. Amongst patients who improved completely, 55.8\% received triple therapy and $44.2 \%$ received sequential therapy.

Association between the G681A polymorphism and response to eradication therapy. Next, whether there was a relation between the G681A polymorphism and the response to eradication therapy was assessed using the results of the HpSA test and the degree of improvement in symptoms. As shown in Table I, there was no significant difference the two CYP2C19 G681A genotypes GG and GA and the response to eradication therapy, using both the HpSA test and degree of the infections symptoms (Fisher's exact test, $\mathrm{P}>0.05$ ) between.

Association between $C$-806T polymorphism with response to eradication therapy. No significant difference was found between the CYP2C19 C-806T genotypes CC, CT and TT and response to eradication therapy based on the HpSA and the degree of symptoms (Fisher's exact test, P>0.05; Table II).

Distribution of responders and non-responders to $H$. pylori eradication amongst the different CYP2C19 phenotypes based on the G681A and C-806T genotypes. The relationship between different CYP2C19 phenotypes and the response to eradication therapy was assessed. There was no significant difference between the different phenotypes of CYP2C19 metabolism and the response to $H$. pylori eradication based on the results of the HpSA test and the degree of $H$. pylori infection (Fisher's exact test, $\mathrm{P}>0.05$; Table III).

\section{Discussion}

H. pylori infection is a common infection worldwide (1). Eradication of infection should be achieved to prevent further the complications when left untreated (11). All eradication regimens include the administration of PPIs, which play an important role in the treatment of $H$. pylori (12). However, eradication is not successful in several cases, due to various issues. One such issue is the variation in the metabolism of 
Table II. Distribution of the C-806T genotype amongst responders and non-responders to eradication therapy based on HpSA test and the degree of symptoms.

\begin{tabular}{lccccr}
\hline & \multicolumn{3}{c}{ C-806Tgenotype, $\mathrm{n}(\%)$} & \\
\cline { 2 - 4 } Method of assessment & $\mathrm{CC}$ & $\mathrm{CT}$ & $\mathrm{TT}$ & Total & P-value $^{\mathrm{a}}$ \\
\hline HpSA test & & & & 0.699 \\
$\quad$ Responder & $30(45.5)$ & $14(21.2)$ & $1(15.0)$ & 45 & \\
$\quad$ Non-responder & $15(22.7)$ & $5(7.6)$ & $1(15.0)$ & 21 & 0.348 \\
$\quad$ Total & 45 & 19 & 2 & 66 & \\
Reporting of symptoms & & & & 40 & \\
Complete improvement & $20(21.3)$ & $19(20.2)$ & $1(1.1)$ & 26 & \\
Partial improvement & $16(17.0)$ & $9(9.5)$ & $1(1.1)$ & 28 & \\
$\quad$ No improvement & $20(21.3)$ & $8(8.5)$ & $0(0.0)$ & 94 \\
$\quad$ Total & 56 & 36 & 2 & \\
\hline
\end{tabular}

${ }^{a}$ Fischer's exact test. HpSA, H. Pylori stool antigen.

Table III. Distribution of the CYP2C19 phenotype amongst responders and non-responders based on the HpSA test and degree of symptoms.

\begin{tabular}{|c|c|c|c|c|c|c|}
\hline \multirow[b]{2}{*}{ Method of assessment } & \multicolumn{4}{|c|}{ C-806Tgenotype, n (\%) } & \multirow[b]{2}{*}{ Total } & \multirow[b]{2}{*}{ P-value } \\
\hline & EM & Het.EM/IM & UM & Het.UM & & \\
\hline HpSA test & & & & & & 0.900 \\
\hline Responder & $29(44.0)$ & $6(9.1)$ & $1(1.5)$ & $9(13.6)$ & 45 & \\
\hline Non-responder & $13(19.7)$ & $2(3.0)$ & $1(1.5)$ & $5(7.6)$ & 21 & \\
\hline Total & 12 & 8 & 2 & 14 & 66 & \\
\hline Reporting of symptoms & & & & & & 0.104 \\
\hline Complete improvement & $19(20.2)$ & $2(2.1)$ & $1(1.1)$ & $18(19.1)$ & 40 & \\
\hline Partial improvement & $11(11.7)$ & $5(5.3)$ & $1(1.1)$ & $9(9.6)$ & 26 & \\
\hline No improvement & $20(21.3)$ & $2(2.1)$ & $0(0.0)$ & $6(6.4)$ & 28 & \\
\hline Total & 50 & 9 & 2 & 33 & 94 & \\
\hline
\end{tabular}

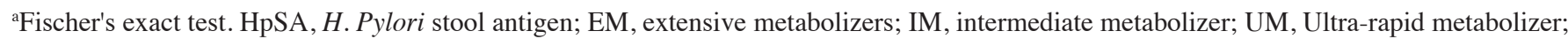
Het, heterogenous.

the PPIs between patients (13). The present study revealed that $\sim 30 \%$ of patients receiving the recommended therapy did not achieve eradication. This may be due to numerous factors other than CYP2C19 polymorphisms, such as age, nutritional status, sex, liver and kidney function, and concomitant medications and diseases (14). Several studies examined the effect of CYP2C19 polymorphisms (in particular G681A and C-806T) on the metabolism of lansoprazole; they reported that carriers of the G681A polymorphism exhibit a lower enzymatic capacity to metabolize lansoprazole, and thus, those subjects possess an increased ability to eradicate $H$. pylori $(15,16)$. Conversely, other studies have reported that carriers of the C-806T polymorphism exhibit increased metabolizing activity of lansoprazole, thus, they are less likely to benefit from the standard dose of lansoprazole (17). However, there are no studies on the effect of these polymorphisms in the eradication of $H$. pylori infection amongst the Jordanian population.
Therefore, the aim of the present study was to investigate the effect of such polymorphisms on the response to eradication regimens. It was shown that there was a difference in the response to eradication therapy between extensive metabolizers (carrying the GG genotype) and intermediate metabolizers (carrying the GA genotype); the majority of patients that did not achieve eradication were extensive metabolizers, not intermediate metabolizers ( 90.5 vs. $9.5 \%$, respectively). Additionally, amongst the extensive metabolizing individuals, it was shown that $35.8 \%$ were non-responders, whereas only $15.4 \%$ of the intermediate metabolizing patients were non-responders. However, these results were statistically insignificant. These results are similar to other previous studies where they found no significant effect on CYP2C19 genetic polymorphisms and the PPI response $(18,19)$. These findings however also contradict several other studies that concluded that there was a significant relation between the G681A polymorphism and 
response to eradication therapy based on lansoprazole $(20,21)$. The difference in the results may be due to the small sample size included in the present study, and differences in ethnicities.

On the other hand, several studies have found similar results of what was observed in the present study $(22,23)$. Although there are controversial results regarding the influence of the CYP2C19 genotype on the effects of PPIs, no association between CYP2C19 genotype and the eradication of $H$. pylori was observed in the present study. These results suggest that the CYP2C19 genotype is not a potential biomarker for determination of the proton pump response, at least amongst Jordanian patients.

There was no significant difference between the efficacy of the triple regimen and sequential regimen. Amongst non-responders, $50 \%$ received the triple regimen and the other $50 \%$ received the sequential regimen. Moreover, amongst responders, 54\% received the triple regimen, whereas $46 \%$ received sequential therapy. Although these findings are in agreement with the findings of Gawrońska-Szklarz et al (23), they conflict with other studies and meta-analyses (24-26), which concluded that there was a significant difference between standard triple therapy and sequential therapy. Those studies showed that the sequential therapy achieved higher eradication rates compared to triple therapy. Regarding the assessment of response after eradication treatment, a significant association existed between the HpSA test results and the degree of symptom improvement; $73.8 \%$ of the responders showed improvement (partial or complete) of symptoms, and $61.1 \%$ of the non-responders showed no improvement of symptoms.

The frequency of the $681 \mathrm{~A}$ mutant allele in Jordanian patients infected with $H$. pylori was found to be $8.2 \%$. The mutant 681A allele frequency within different populations ranged from 7.8 to $45.5 \%$. 681A allele frequency amongst several populations was similar to the Jordanian, including Russian (27), Italian (28), Norwegian (29), Egyptian (30) and Ethiopian (8) cohorts. Conversely, several other populations, including Faroese (31), Danish (31), African Americans (32). Chinese (33), Korean (34) and Japanese (10) showed significant differences in G681A allele frequencies compared with the Jordanian patients infected with $H$. pylori. Regarding the variant allele $-806 \mathrm{~T}$, the frequency was found to be $25.2 \%$ in the present study population. This was similar to the allele frequency of Faroese (31), Danish (31), African American (32) and Norwegian (29). However, Chinese (8), Korean (34) and Japanese (10) showed a difference in the -806 allele frequency compared with the present study.

One of the limitations of the present study is the relatively small sample size of the $H$. pylori infected patients, which resulted in a lack of patients with a poor CYP2C19 metabolizer phenotype. This may result in a bias in the conclusions drawn regarding the influence of the CYP2C19 genotype on the response to lansoprazole. Further studies with larger cohorts of Jordanian patients are required to confirm the findings of the present study. In addition, this study did not investigate the association of CYP2C19 genotype with the patients morbidity and complications secondary to $H$. pylori infection. These clinical factors will be taken into consideration in the future studies regarding the influence of CYP2C19 genotype on lansoprazole response.
In conclusion, there was no significant association found between the CYP2C19 G681A and C-806T polymorphisms and the response to eradication therapy amongst Jordanian patients infected with $H$. pylori.

\section{Acknowledgements}

The authors would like to thank Deanship of Scientific Research, The University of Jordan for supporting this research.

\section{Funding}

This research was funded by the Deanship of Scientific Research, The University of Jordan (grant no. 21/2014/2015).

\section{Availability of data and materials}

The datasets used and/or analyzed during the present study are available from the corresponding author on reasonable request.

\section{Authors' contributions}

BB conducted the experimental work. MR and ZA contributed to the clinical evaluation and analysis of the patients. BB, MZ and $\mathrm{YJ}$ analyzed the data. $\mathrm{MZ}$ and BB wrote this manuscript and YJ revised it. All authors have read and approved the final manuscript.

\section{Ethics approval and consent to participate}

Every patient provided signed informed consent to participate in this study. The study and the consent form were approved by the Institutional Review Board of The University of Jordan Hospital (Amman, Jordan).

\section{Patient consent for publication}

Not applicable.

\section{Competing interests}

The authors declare that they have no competing interests.

\section{References}

1. Malaty HM and Nyren O: Epidemiology of Helicobacter pylori infection. Helicobacter 8 (Suppl 1): 8-12, 2003.

2. Chey WD and Wong BC; Practice Parameters Committee of the American College of Gastroenterology: American College of Gastroenterology guideline on the management of Helicobacter pylori infection. Am J Gastroenterol 102: 1808-1825, 2007.

3. Shin JM and Sachs G: Pharmacology of proton pump inhibitors. Curr Gastroenterol Rep 10: 528-534, 2008.

4. Lee SJ: Clinical Application of CYP2C19 Pharmacogenetics Toward More Personalized Medicine. Front Genet 3: 318, 2013.

5. Ishizaki T and Horai Y: Review article: Cytochrome P450 and the metabolism of proton pump inhibitors--emphasis on rabeprazole. Aliment Pharmacol Ther 13 (Suppl 3): 27-36, 1999.

6. Zalloum I, Hakooz N and Arafat T: Genetic polymorphism of CYP2C19 in a Jordanian population: Influence of allele frequencies of CYP2C19*1 and CYP2C19*2 on the pharmacokinetic profile of lansoprazole. Mol Biol Rep 39: 4195-4200, 2012.

7. Li-Wan-Po A, Girard T, Farndon P, Cooley C and Lithgow J: Pharmacogenetics of CYP2C19: Functional and clinical implications of a new variant CYP2C19*17. Br J Clin Pharmacol 69: 222-230, 2010. 
8. Sim SC, Risinger C, Dahl ML, Aklillu E, Christensen M, Bertilsson $\mathrm{L}$ and Ingelman-Sundberg $\mathrm{M}$ : A common novel CYP2C19 gene variant causes ultrarapid drug metabolism relevant for the drug response to proton pump inhibitors and antidepressants. Clin Pharmacol Ther 79: 103-113, 2006.

9. Charan J and Biswas T: How to calculate sample size for different study designs in medical research? Indian J Psychol Med 35: 121-126, 2013.

10. Sugimoto K, Uno T, Yamazaki $\mathrm{H}$ and Tateishi T: Limited frequency of the CYP2C19*17 allele and its minor role in a Japanese population. Br J Clin Pharmacol 65: 437-439, 2008.

11. Dowdle WR: The principles of disease elimination and eradication. Bull World Health Organ 76 (Suppl 2): 22-25, 1998.

12. Yang JC, Lu CW and Lin CJ: Treatment of Helicobacter pylori infection: Current status and future concepts. World J Gastroenterol 20: 5283-5293, 2014.

13. Mégraud F and Lamouliatte $\mathrm{H}$ : Review article: The treatment of refractory Helicobacter pylori infection. Aliment Pharmacol Ther 17: 1333-1343, 2003.

14. Jarrar Y and Lee SJ: The functionality of UDP-Glucuronosyltransferase genetic variants and their association with drug responses and human diseases. J Pers Med 11: 11, 2021.

15. Kuo CH, Lu CY, Shih HY, Liu CJ, Wu MC, Hu HM, Hsu WH, Yu FJ, Wu DC and Kuo FC: CYP2C19 polymorphism influences Helicobacter pylori eradication. World J Gastroenterol 20 : 16029-16036, 2014.

16. Zhao F, Wang J, Yang Y, Wang X, Shi R, Xu Z, Huang Z and Zhang G: Effect of CYP2C19 genetic polymorphisms on the efficacy of proton pump inhibitor-based triple therapy for Helicobacter pylori eradication: A meta-analysis. Helicobacter 13 532-541, 2008

17. Shirasaka Y, Chaudhry AS, McDonald M, Prasad B, Wong T, Calamia JC, Fohner A, Thornton TA, Isoherranen N, Unadkat JD, etal: Interindividual variability of CYP2C19-catalyzed drug metabolism due to differences in gene diplotypes and cytochrome P450 oxidoreductase content. Pharmacogenomics J 16: 375-387, 2016.

18. Miki I, Aoyama N, Sakai T, Shirasaka D, Wambura CM, Maekawa S, Kuroda K, Tamura T, Kita T, Sakaeda T, et al: Impact of clarithromycin resistance and CYP2C19 genetic polymorphism on treatment efficacy of Helicobacter pylori infection with lansoprazole- or rabeprazole-based triple therapy in Japan. Eur J Gastroenterol Hepatol 15: 27-33, 2003.

19. Take S, Mizuno M, Ishiki K, Nagahara Y, Yoshida T, Inaba T, Yamamoto K, Okada H, Yokota K, Oguma K, et al: Interleukin-1beta genetic polymorphism influences the effect of cytochrome P 2C19 genotype on the cure rate of 1-week triple therapy for Helicobacter pylori infection. Am J Gastroenterol 98 : 2403-2408, 2003.

20. Kawabata H, Habu Y, Tomioka H, Kutsumi H, Kobayashi M, Oyasu K, Hayakumo T, Mizuno S, Kiyota K, Nakajima M, et al: Effect of different proton pump inhibitors, differences in CYP2C19 genotype and antibiotic resistance on the eradication rate of Helicobacter pylori infection by a 1-week regimen of proton pump inhibitor, amoxicillin and clarithromycin. Aliment Pharmacol Ther 17: 259-264, 2003.

21. Okudaira K, Furuta T, Shirai N, Sugimoto M and Miura S: Concomitant dosing of famotidine with a triple therapy increases the cure rates of Helicobacter pylori infections in patients with the homozygous extensive metabolizer genotype of CYP2C19. Aliment Pharmacol Ther 21: 491-497, 2005.
22. Kurzawski M, Gawrońska-Szklarz B, Wrześniewska J, Siuda A, Starzyńska T and Droździk M: Effect of CYP2C19*17 gene variant on Helicobacter pylori eradication in peptic ulcer patients. Eur J Clin Pharmacol 62: 877-880, 2006.

23. Gawrońska-Szklarz B, Siuda A, Kurzawski M, Bielicki D, Marlicz W and Droździk M: Effects of CYP2C19, MDR1, and interleukin 1-B gene variants on the eradication rate of Helicobacter pylori infection by triple therapy with pantoprazole, amoxicillin, and metronidazole. Eur J Clin Pharmacol 66: 681-687, 2010.

24. Park HG, Jung MK, Jung JT, Kwon JG, Kim EY, Seo HE, Lee JH, Yang CH, Kim ES, Cho KB, et al: Randomised clinical trial: A comparative study of 10-day sequential therapy with 7-day standard triple therapy for Helicobacter pylori infection in naïve patients. Aliment Pharmacol Ther 35: 56-65, 2012.

25. Choi HS, Chun HJ, Park SH, Keum B, Seo YS, Kim YS, Jeen YT, Um SH, Lee HS, Kim CD, et al: Comparison of sequential and 710-, 14-d triple therapy for Helicobacter pylori infection. World J Gastroenterol 18: 2377-2382, 2012.

26. Liou JM, Chen CC, Chen MJ, Chen CC, Chang CY, Fang YJ, Lee JY, Hsu SJ, Luo JC, Chang WH, et al; Taiwan Helicobacter Consortium: Sequential versus triple therapy for the first-line treatment of Helicobacter pylori: A multicentre, open-label, randomised trial. Lancet 381: 205-213, 2013.

27. Gaikovitch EA, Cascorbi I, Mrozikiewicz PM, Brockmöller J, Frötschl R, Köpke K, Gerloff T, Chernov JN and Roots I: Polymorphisms of drug-metabolizing enzymes CYP2C9, CYP2C19, CYP2D6, CYP1A1, NAT2 and of P-glycoprotein in a Russian population. Eur J Clin Pharmacol 59: 303-312, 2003.

28. Scordo MG, Aklillu E, Yasar U, Dahl ML, Spina E and IngelmanSundberg M: Genetic polymorphism of cytochrome P450 $2 \mathrm{C} 9$ in a Caucasian and a black African population. Br J Clin Pharmacol 52: 447-450, 2001.

29. Rudberg I, Mohebi B, Hermann M, Refsum H and Molden E: Impact of the ultrarapid CYP2C19*17 allele on serum concentration of escitalopram in psychiatric patients. Clin Pharmacol Ther 83: 322-327, 2008

30. Hamdy SI, Hiratsuka M, Narahara K, El-Enany M, Moursi N, Ahmed MS and Mizugaki M: Allele and genotype frequencies of polymorphic cytochromes P450 (CYP2C9, CYP2C19, CYP2E1) and dihydropyrimidine dehydrogenase (DPYD) in the Egyptian population. Br J Clin Pharmacol 53: 596-603, 2002.

31. Pedersen RS, Brasch-Andersen C, Sim SC, Bergmann TK, Halling J, Petersen MS, Weihe P, Edvardsen H, Kristensen VN, Brøsen K, et al: Linkage disequilibrium between the CYP2C19*17 allele and wildtype CYP2C8 and CYP2C9 alleles: Identification of CYP2C haplotypes in healthy Nordic populations. Eur J Clin Pharmacol 66: 1199-1205, 2010.

32. Bravo-Villalta HV, Yamamoto K, Nakamura K, Bayá A, Okada Y and Horiuchi R: Genetic polymorphism of CYP2C9 and CYP2C19 in a Bolivian population: An investigative and comparative study. Eur J Clin Pharmacol 61: 179-184, 2005.

33. Chen L, Qin S, Xie J, Tang J, Yang L, Shen W, Zhao X, Du J, He G, Feng G, et al: Genetic polymorphism analysis of CYP2C19 in Chinese Han populations from different geographic areas of mainland China. Pharmacogenomics 9: 691-702, 2008.

34. Lee SJ, Kim WY, Kim H, Shon JH, Lee SS and Shin JG: Identification of new CYP2C19 variants exhibiting decreased enzyme activity in the metabolism of S-mephenytoin and omeprazole. Drug Metab Dispos 37: 2262-2269, 2009. 